\title{
Response to Pontoon and Pendulum Motion at Wave Energy Converter Based on Pendulum System
}

\author{
I. S. Arief ${ }^{1}, I$. K. A. P. Utama ${ }^{2}, R$. Hantoro ${ }^{3}, J$. Prananda ${ }^{3}, Y$. Safitri ${ }^{2}, T$. Rachmattra A. ${ }^{3}$, and Rindu F. K. ${ }^{3}$ \\ ${ }^{1}$ Department of Naval Architecture, Institute of Technology Sepuluh Nopember, Surabaya, Indonesia \\ ${ }^{2}$ Department of Physics Engineering, Institute of Technology Sepuluh Nopember, Surabaya, Indonesia \\ ${ }^{3}$ Department of Marine Engineering, Institute of Technology Sepuluh Nopember, Surabaya, Indonesia
}

\begin{abstract}
Energy conversion technology derived from ocean wave energy has been developed, one of them is the Power Wave sea- Pendulum System (PLTGL-SB). PLTGL composed of a pontoon which is subjected to the excitation force of ocean waves and will move the pendulum on the top of the pontoon. This study aims to analyze the best shape for PLTGL- SB's pontoon and determine the largest deviation generated due to the movement of the pendulum vertical pontoon. Pontoon shapes studied are pontoon consisting of a large cylinder in the middle and there are two boats on the right and left, like a trimaran ship. Variations were made in this study consisted of variations of length and height boats, the draft height, wave period, the mass and the length of the pendulum arm. Best pontoon shape is determined by simulating the shape of a pontoon with Computational Fluid Dynamic (CFD). Pendulum deviation obtained by mathematical modeling pontoon two degrees of freedom (roll) and pendulum. Based on the chart Response Amplitude Operator (RAO) pontoon shape is best for PLTGL-SB is a pontoon with a $2 / 3$ full large cylinder diameter, $1.5 \mathrm{~cm}$ height boats, catamarans length of $41.5 \mathrm{~cm}$. Based on the results of a mathematical model of the largest deviation of the pendulum is generated when the pontoon is placed in the period of $0.8 \mathrm{~s}$, with a mass and pendulum arm lengths are $19.9 \mathrm{~g}$ and $10.6 \mathrm{~cm}$.
\end{abstract}

\section{Introduction}

According to General Directorate (Ditjen) of Renewable Energy and Conservation Energy (EBTKE) in 2013, hydro energy (ocean) is the one of potential renewable energy in Indonesia. Indonesia has large sea three times of its land, in the amount of 3,544,743.9 km2. Ocean energy source consists of three types, i.e. ocean heat energy, tidal energy, and ocean wave energy.

Ocean wave energy started to study more than 30 years ago (Hongda Shi, 2014) [1]. Nowadays, conversion energy technology from ocean wave energy is already expanded, i.e. oscillating water column installed pendulum system in the shoreline, shelter duck system, and Pelamis water converter (Rodrigues, 2010) [2].

Ocean wave energy device such as Oscillating Water Columns (OWC) changes the movement of wave in air cylinder column to produce pressured air and furthermore it used to move a turbine and electric generator. OWC has an advantage because it has a little-submersed part in the water. OWC technology also has a disadvantage because it limited by water depth so it is not allowed to be installed in the deep sea. Appropriateness study of OWC has done by Shi et al (Hongda Shi, 2014) by modeling air to optimize room scale and turbine pressure so that produce a large efficiency of electrical power (Hongda Shi, 2014). Another technology created to resolve the limitations of OWC is floating dish. Floating dish first time installed by the Ocean University of China. Floating dish consists of underwater part i.e. piston to get ocean wave and upper part i.e. generator to convert the movement of piston become electrical energy (KS. Choi, 2012). Floating dish use Heave movement from an ocean wave. The technology which uses piston movement to get ocean wave i.e. Pelamis, Duck and Eagle converter developed Guangdong Institution of Energy Conversion, China (Hongda Shi, 2014).

In Indonesia, OWC technology started in 2004 built by BPPT especially BPDP (Balai Pengkajian Dinamika Pantai). OWC prototype built at Parang Racung Beach, Gunung Kidul. Before OWC, the forerunner technology is Ocean Wave Energy Power Plant - Pendulum System (PLTGL-SB). Study of PLTGL-SB start in 2002 by Zamrisyaf, an employee of the research center and development PT. Perusahaan Listrik Negara (PLN).

Ocean wave energy power plant using pendulum system from Zamrisyaf consist of pontoon and pendulum system with pontoon dimension i.e. L: $6 \mathrm{~m}, \mathrm{~B}: 3 \mathrm{~m}, \mathrm{Tp}$ : $1.5 \mathrm{~s}$ and D: $2 \mathrm{~m}$ with a slope angle of the hull is 450 . There are two types of pendulum based on position i.e. pendulum placed vertical and horizontal. The first test of PLTGL-SB was done in Ulank Karang beach, Padang in 2002 and got a patent in 2009 with horizontal and vertical pendulum placed on drums.

The concept of PLTGL- SB continues to enhance by some studies. In 2012, PLTGL-SB was developing by the varied shape of octagonal pontoon arranged become

*orresponding author: kutama@na.its.ac.id, teuku14@mhs.ne.its.ac.id 
triangle (tripod) in the height of wave $0.5 \mathrm{~m}$ and $1.5 \mathrm{~m}$ (Yasin Bestari, 2013) [3]. This research based on simulation using software Numeca to get the optimum motion of pontoon for PLTGL-SB. In 2013, research of PLTGL-SB developed by Saadilah Akbar by varied the slope of pontoon hull in height of ocean wave i.e. $1 \mathrm{~m}$ and $1.5 \mathrm{~m}$. In 2014, research is continued by doing an experimental study in pontoon shape. Pontoon shape i.e. oval, ball, and tube. The biggest force production obtained in a ball shape, because in a ball shape has largest water surface area than another shape. Known that by the increase of length in water exposed section then it will affect power that received pontoon (Cahyadi, 2014).

The electricity produces from pendulum system lack to fulfill society energy needs. So, the development of this wave energy converter requires an acceleration process so that the scale-up process is required through the increase of PLTGL-SB power capacity[4].

Research i.e. analyze PLTGL-SB with pontoon shape consist of three cylinders; one big cylinder and two small cylinders (jukung) as a balancer. Variation in this research is length variation of jukung arm, the height of jukung and height of water draft. Then the influences of that variation will analyze by software Ansys Aqwa until found the best pontoon model for PLTGL-SB. Next, make the formulation of the mathematic model to know the slope of the pendulum in one degree of freedom pontoon motion one-degree pendulum movement. Validation of simulation using experiment study.

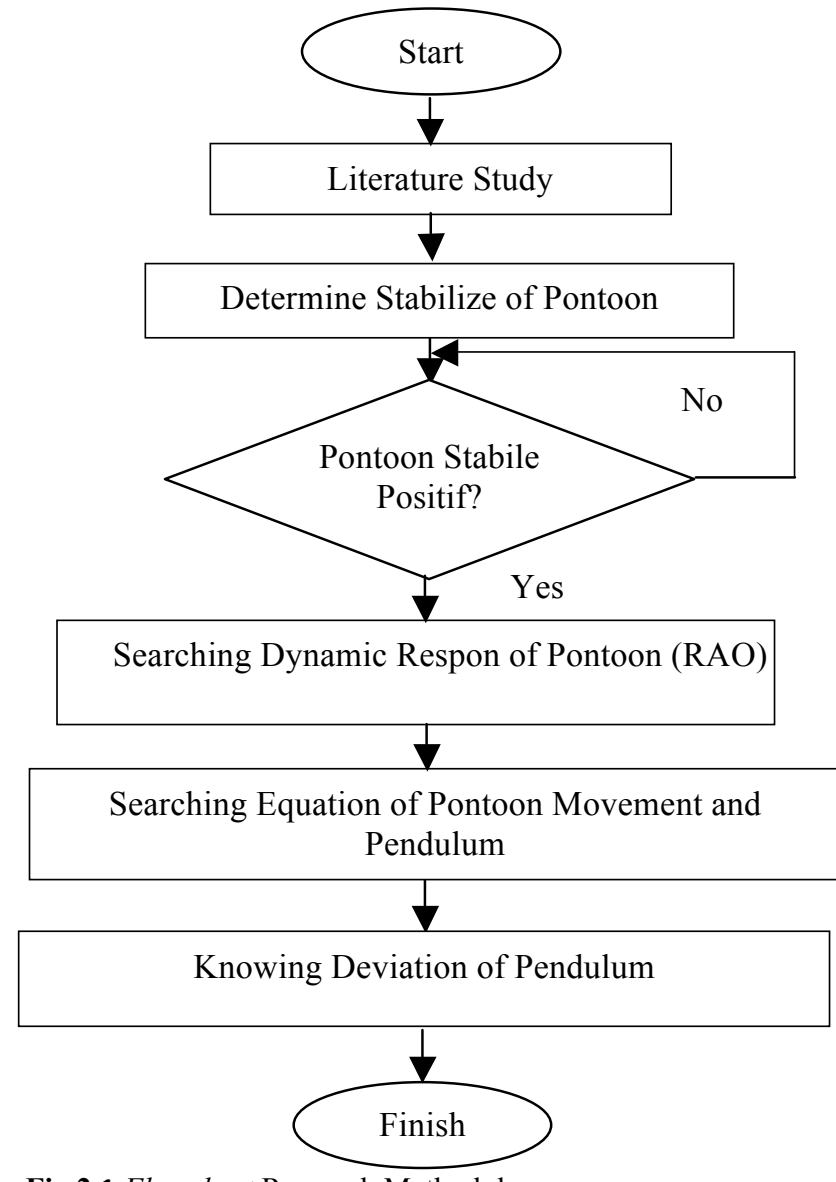

Fig 2.1 Flowchart Research Methodology.

\section{Methodology}

\subsection{Research Flow Diagram}

Generally, the steps are a draw in flow diagram i.e. Picture 2.1 below. The process of this research begins with a study of literature on the research of Marine Wave Power Generation Pendulum System (PLTGL-SB) which already existed before. The basic things that the author studied at the stage of literature study are the science of ocean waves, the movement of marine buildings, the response of marine buildings to the wave excitation style. After that, the authors determine the stability of the pontoon. Determination of stability is determined by three points namely, Center of Gravity (COG), Center of Buoyancy (COB), and point metacenter. Pontoons that can already be said to be positively stable if the position of the metacenter point above the point of COG and COB. Stable positive means that the pontoon will return to its original position if the pontoon is exposed to the excitation force of the ocean waves. After that, the author also studied the theory of CFDs for floating marine buildings. After that, the authors retrieve the data into the towing tank where the instrument test, the wave period, and the wave amplitudes through the experimental circuit. After performing the data retrieval, the writer analyses the pontoon response to the wave excitation style to achieve the first goal of this final project, which is to know the best pontoon shape for PLTGL-SB with various variations. Pontoons motion response is obtained by simulating the pontoon using Ansys Hydrodynamic Diffraction or Ansys Aqwa. The simulation results on the hydrodynamic diffraction will be known response value amplitude operator (RAO) or pontoon response due to the coming ocean waves. The results of the simulation of RAO pontoons analysis conducted as many as 16 variations. Variables that are varied include water laden height. Different water will affect the magnitude of the movement of ships (marine buildings) floating (Mulyawan, 2010). The high water-laden difference will affect the COB point value and the Metacentre point. Jukung variation is done because the length of jukung will affect the stability of the ship (Barras, 2006).

The number of variations shown in table 3.1. The variations used to analyze the variations of pontoon 1,2 , 9,11 , and 15 . While the pendulum mass variation and the height of the pendulum arm will affect the COG pontoon.

The second objective of this study, namely to know the size of the pendulum, is achieved by performing mathematical models until the equations of motion and the pendulum response is obtained. Mathematical modeling is performed on one degree of free pontoon (roll) and one-degree pendulum free. Table 3.2 is a detail of pendulum variations. Variations of pendulum mass and pendulum sleeves were performed to find out the deviations to be generated pendulum and sought the largest deviation to be converted into electrical energy. Variations used to analyze data are variations to 5, 6, 9, 
10,21 and 23.

Table 1. Variation of Pontoon.

\begin{tabular}{|c|c|c|c|c|c|}
\hline & Draft & $\begin{array}{l}\text { Height of } \\
\text { Outrigger } \\
\text { (cm) }\end{array}$ & $\begin{array}{l}\text { Length of } \\
\text { Outrigger } \\
\text { (cm) }\end{array}$ & 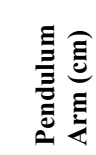 & $\begin{array}{l}\text { Weight of } \\
\text { Pendulum } \\
\text { (gr) }\end{array}$ \\
\hline 1 & $1 / 2 \mathrm{D}$ & 4 & 49.5 & 16.5 & 40.6 \\
\hline 2 & $1 / 2 \mathrm{D}$ & 4 & 49.5 & 16.5 & 19.9 \\
\hline 3 & $1 / 2 \mathrm{D}$ & 4 & 49.5 & 10.67 & 40.6 \\
\hline 4 & $1 / 2 \mathrm{D}$ & 4 & 49.5 & 10.67 & 19.9 \\
\hline 5 & $1 / 2 \mathrm{D}$ & 4 & 41.5 & 16.5 & 40.6 \\
\hline 6 & $1 / 2 \mathrm{D}$ & 4 & 41.5 & 16.5 & 19.9 \\
\hline 7 & $1 / 2 \mathrm{D}$ & 4 & 41.5 & 10.67 & 40.6 \\
\hline 8 & $1 / 2 \mathrm{D}$ & 4 & 41.5 & 10.67 & 19.9 \\
\hline 9 & $2 / 3 \mathrm{D}$ & 1.5 & 49.5 & 16.5 & 40.6 \\
\hline 10 & $2 / 3 \mathrm{D}$ & 1.5 & 49.5 & 16.5 & 19.9 \\
\hline 11 & $2 / 3 \mathrm{D}$ & 1.5 & 49.5 & 10.67 & 40.6 \\
\hline 12 & $2 / 3 \mathrm{D}$ & 1.5 & 49.5 & 10.67 & 19.9 \\
\hline 13 & $2 / 3 \mathrm{D}$ & 1.5 & 41.5 & 16.5 & 40.6 \\
\hline 14 & $2 / 3 \mathrm{D}$ & 1.5 & 41.5 & 16.5 & 19.9 \\
\hline 15 & $2 / 3 \mathrm{D}$ & 1.5 & 41.5 & 10.67 & 40.6 \\
\hline 16 & $2 / 3 \mathrm{D}$ & 1.5 & 41.5 & 10.67 & 19.9 \\
\hline
\end{tabular}

Table 2. Variation of Pendulum.

\begin{tabular}{|l|l|l|l|l|}
\hline Variation & Draft & $\begin{array}{l}\text { Wave Period } \\
\text { (s) }\end{array}$ & $\begin{array}{l}\text { Mass } \\
\text { (gr) }\end{array}$ & $\begin{array}{l}\text { Height of } \\
\text { Arm } \\
\text { (cm) }\end{array}$ \\
\hline 1 & $1 / 2 \mathrm{D}$ & 0.4 & 40.6 & 16.5 \\
\hline 2 & $1 / 2 \mathrm{D}$ & 0.4 & 40.6 & 10.67 \\
\hline 3 & $1 / 2 \mathrm{D}$ & 0.4 & 19.9 & 16.5 \\
\hline 4 & $1 / 2 \mathrm{D}$ & 0.4 & 19.9 & 10.67 \\
\hline 5 & $1 / 2 \mathrm{D}$ & 0.6 & 40.6 & 16.5 \\
\hline 6 & $1 / 2 \mathrm{D}$ & 0.6 & 40.6 & 10.67 \\
\hline 7 & $1 / 2 \mathrm{D}$ & 0.6 & 19.9 & 16.5 \\
\hline 8 & $1 / 2 \mathrm{D}$ & 0.6 & 19.9 & 10.67 \\
\hline 9 & $1 / 2 \mathrm{D}$ & 0.8 & 40.6 & 16.5 \\
\hline 10 & $1 / 2 \mathrm{D}$ & 0.8 & 40.6 & 10.67 \\
\hline 11 & $1 / 2 \mathrm{D}$ & 0.8 & 19.9 & 16.5 \\
\hline 12 & $1 / 2 \mathrm{D}$ & 0.8 & 19.9 & 10.67 \\
\hline 13 & $2 / 3 \mathrm{D}$ & 0.4 & 40.6 & 16.5 \\
\hline 14 & $2 / 3 \mathrm{D}$ & 0.4 & 40.6 & 10.67 \\
\hline 15 & $2 / 3 \mathrm{D}$ & 0.4 & 19.9 & 16.5 \\
\hline 16 & $2 / 3 \mathrm{D}$ & 0.4 & 19.9 & 10.67 \\
\hline 17 & $2 / 3 \mathrm{D}$ & 0.6 & 40.6 & 16.5 \\
\hline 18 & $2 / 3 \mathrm{D}$ & 0.6 & 40.6 & 10.67 \\
\hline 19 & $2 / 3 \mathrm{D}$ & 0.6 & 19.9 & 16.5 \\
\hline 20 & $2 / 3 \mathrm{D}$ & 0.6 & 19.9 & 10.67 \\
\hline 21 & $2 / 3 \mathrm{D}$ & 0.8 & 40.6 & 16.5 \\
\hline 22 & $2 / 3 \mathrm{D}$ & 0.8 & 40.6 & 10.67 \\
\hline 23 & $2 / 3 \mathrm{D}$ & 0.8 & 19.9 & 16.5 \\
\hline 24 & $2 / 3 \mathrm{D}$ & 0.8 & 19.9 & 10.67 \\
\hline & & & & \\
\hline
\end{tabular}

\subsection{Design of PLTGL}

The design consists of a pontoon with three cylinders. One large cylinder and two small cylinders (jukung) located on the right and left as a counterweight. The pendulum form studied is a vertical pendulum. Pontoons with such shapes are the object of CFD simulation and observed the motion response due to the excitation force of the incoming waves. The following is a detailed measure of the pontoon and pendulum used in this study:
Table 3. Geometry of PLTGL.

\begin{tabular}{|l|l|}
\hline \multicolumn{2}{|l|}{ Geometry of PLTGL } \\
\hline Diameter of Big Cylinder (D) & $16.5 \mathrm{~cm}$ \\
\hline Thickness of Big Cylinder & $0.7 \mathrm{~cm}$ \\
\hline Diameter of Small Cylinder (Jukung) & $4 \mathrm{~cm}$ \\
\hline Thickness of Small Cylinder & $0.2 \mathrm{~cm}$ \\
\hline Length of Big Cylinder & $32 \mathrm{~cm}$ \\
\hline Length of small Cylinder & $32 \mathrm{~cm}$ \\
\hline Cylinder Density & $1.39 \mathrm{gr} / \mathrm{cm}^{3}$ \\
\hline Water Draft & $1 / 2 \mathrm{D}$ and $2 / 3 \mathrm{D}$ \\
\hline Height of Jukung & $1.5 \mathrm{~cm}$ and $4 \mathrm{~cm}$ \\
\hline Length of Plat & $32 \mathrm{~cm}$ \\
\hline Breadth of Plat & $17 \mathrm{~cm}$ \\
\hline Plat Density & $1.2 \mathrm{gr} / \mathrm{cm}^{3}$ \\
\hline Pendulum Pole Height & $2.75 \mathrm{~cm}$ (from plate) \\
\hline Pendulum Pole Arm & $23 \mathrm{~cm}$ \\
\hline Pendulum Mass & $40.6 \mathrm{gr}$ and $19.9 \mathrm{gr}$ \\
\hline
\end{tabular}

The next stage is to calculate the stability of the pontoon, by determining the point of the centre of gravity, the centre of buoyancy, and the point of metacentre. The meta centrum point is searched using the following formula,

$$
M=\frac{I_{O}}{V}-A_{o} B_{0}
$$

By looking for a meta centre point, we can see whether the pontoon is stable or not. Based on meta Centrum values it can be determined that, if $\mathrm{M}$ is above the point of weight then the object is said to be stable, $\mathrm{M}=$ centre of gravity than the pontoon is said to be neutral stability, and if $\mathrm{M}$ is below the point of weight it is said to be unstable. While the buoyancy point sought by using software Maxsurf. COB is likened to COG from the submerged parts, so the search will be the same as COG with a record of just the submerged pontoon that is used as a review. The COG (Centre of Gravity) point is searched by using equation (2.2).

$$
x_{0}=\frac{\sum_{i=1}^{n} w_{i} x_{i}}{\sum_{i=1}^{n} w_{i}} \quad y_{0}=\frac{\sum_{i=1}^{n} w_{i} y_{i}}{\sum_{i=1}^{n} w_{i}} \quad z_{0}=\frac{\sum_{i=1}^{n} w_{i} z_{i}}{\sum_{i=1}^{n} w_{i}}
$$

The results of the calculation of the three points on pontoon $1 / 2 \mathrm{D}$ and $2 / 3 \mathrm{D}$ are as follows:

Table 3. Calculation of Pontoon.

\begin{tabular}{|l|l|l|}
\hline \multicolumn{1}{|c|}{ Position from Keel } & \multicolumn{1}{|c|}{ Draft 1/2 D } & \multicolumn{1}{c|}{ Draft 2/3 D } \\
\hline Draft & $8.25 \mathrm{~cm}$ & $11 \mathrm{~cm}$ \\
\hline COB & $4.752 \mathrm{~cm}$ & $6.345 \mathrm{~cm}$ \\
\hline Metacentre & $12.17 \mathrm{~cm}$ & $11.78 \mathrm{~cm}$ \\
\hline Dyed Volume & $0.00342 \mathrm{~m}^{3}$ & $0.00485 \mathrm{~m}^{3}$ \\
\hline Dyed Mass & $3.42 \mathrm{~kg}$ & $4.85 \mathrm{~kg}$ \\
\hline
\end{tabular}




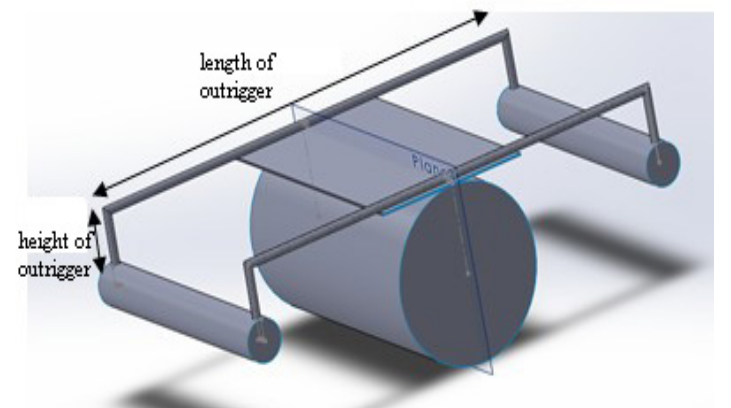

Fig 2.2 Picture of PLTGL-SB 3D

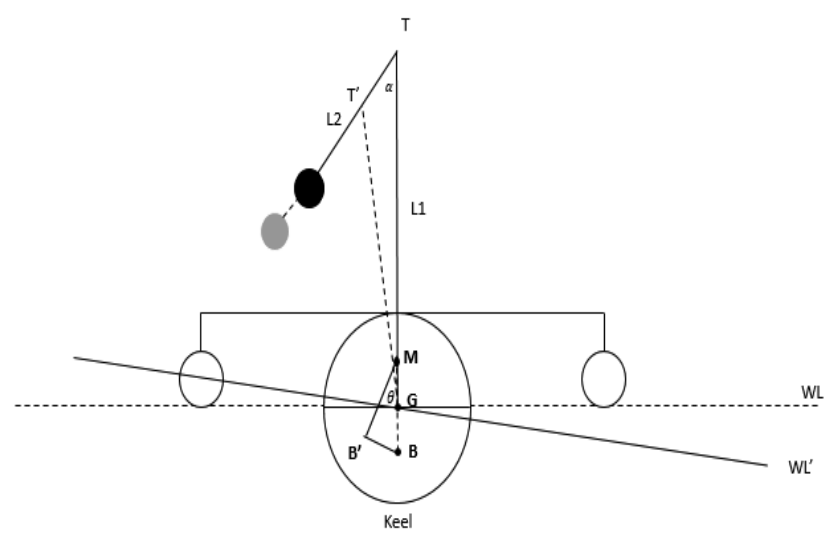

Fig 2.3 PLTGL-SB Front Side

\subsection{CFD Simulation of Pontoon}

\subsubsection{Pontoon Geometry}

Large cylinders and two jukung are made of one unit in the workbench. The geometry of the pontoon is made up of several models based on the variations to be performed. The geometry of the pontoon is made up of 4 models. The geometry of the pontoons is made with a $1 / 2$ D load with a jukung length of $49.5 \mathrm{~cm}$ and $41.5 \mathrm{~cm}$. Then made also a pontoon geometry with laden $2 / 3 \mathrm{D}$ with jukung length $49.5 \mathrm{~cm}$ and $41.5 \mathrm{~cm}$. Figure 2.3 is an example of a pontoon geometry image in a workbench.

\subsubsection{Pontoon Model}

After going through the stage of making geometry the next stage is to model the pontoon. Stage modeling pontoons things that must input, including:

- Water depth, on the geometry

- Mass fluid type (water), on the geometry

- Water size on the $\mathrm{x}$ and $\mathrm{y}$-axes, in the geometry section

- COG point (Centre of Gravity), at the point mass

- Grating radius, at the point mass.

The depth of the waters input according to the depth of the tank where the experiments tool is done, i.e. as deep as 2 meters. Water size on the $\mathrm{x}$ axis is $50 \mathrm{~m}$ and $y$-axis of $3 \mathrm{~m}$, according to the tank where the experiment is conducted. Determination of $\mathrm{COG}$ point and girth radius is done by manual calculation using Microsoft excel for each variation of the pontoon.

\subsubsection{Meshing}

Meshing is the process of splitting the domain into small parts or become elements. Meshing on Ansys Hydrodynamic Diffraction can be automatically generated by inputting defeaturing tolerance and maximum element size. In the Generated Mesh information section will display the number of nodes and elements meshing results. The maximum number of elements in Ansys Hydrodynamic Diffraction is as many as 18,000 elements and 12,000 elements of diffracted elements. A number of nodes and element is the number of nodes and elements that meshing results. The number of nodes (diffracting body) and a number of an element (diffracting body) are the numbers of nodes and elements on a water-immersed pontoon.

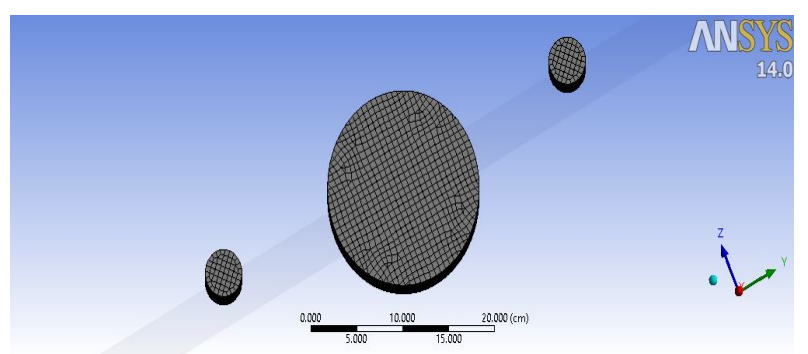

Fig 2. 4 Result of Meshing Pontoon

Table 4. Detail of Mesh.

\begin{tabular}{|l|l|}
\hline \multicolumn{2}{|l|}{ Detail of Mesh } \\
\hline Max Element Size & $1 \mathrm{~cm}$ \\
\hline Defeaturing Tolerance & $0.5 \mathrm{~cm}$ \\
\hline Number of Nodes & 8910 \\
\hline Number of Elements & 8952 \\
\hline Number of Nodes (Diffracting Bodies) & 3127 \\
\hline
\end{tabular}

\subsubsection{Pre-Processing}

After doing meshing the next stage is the setup stage. At this stage, the input is coming to the wave direction. The direction of the wave coming is adjusted by experiment, i.e. the direction of 900 or the direction of the wave coming from the body of the pontoon. After inputting the wave direction the next stage is to input the wave frequency range. The default wave frequency conditions can be defined in range and single. At this stage, the wave frequency is input manually within a range. The frequency range used is between $1 \mathrm{~Hz}$ and $5 \mathrm{~Hz}$. 


\subsubsection{Post-Processing}

The final stage of simulation on hydrodynamic diffraction is solution or result. In this section, the author can determine what results want to appear. To know the response of the pontoon due to ocean waves, the RAO graph (Response Amplitude Operator) is displayed. This study will only analyze the results of RAO graphs contained in the solution section.

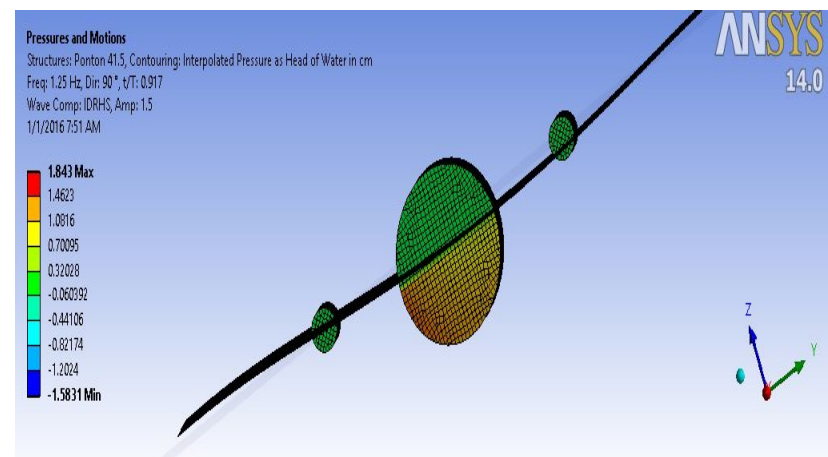

Fig 2. 5 Simulation result with Incoming Wave

\subsection{Mathematics Formulation of Pontoon Movement and Pendulum}

Mathematical modelling of pontoon and pendulum motion is obtained from the calculation of the length of point B (Buoyancy), Metacentre (M), and point $G$ (Gravity). The third distance of this point is calculated from the point of the pontoon keel. The equation of motion is obtained by simulating the motion of one degree of freedom pontoon (roll) and one degree of freedom pendulum with Lagrange law. At 1/2-diameter draft large cylinders, the following values are known:

B (Centre of Buoyancy): $4.752 \mathrm{~m}$ from keel

M (Metacentre): $12.17 \mathrm{~cm}$ from keel

$\mathrm{G}$ (Centre of Gravity): $8.25 \mathrm{~cm}$ from keel

$\overline{\text { GT }}$ (Length from $\mathrm{G}$ point to Pendulum Pole): $42.05 \mathrm{~cm}$

At draft 2/3 large diameter cylinder, known value as follows:

B (Centre of Buoyancy): $6.345 \mathrm{~m}$ from keel

M (Metacentre): $11.78 \mathrm{~cm}$ from keel

$\mathrm{G}$ (Centre of Gravity): $11 \mathrm{~cm}$ from keel

$\overline{\text { GT }}$ (Length from $\mathrm{G}$ point to Pendulum Pole): $31.05 \mathrm{~cm}$

The method of searching the equation of motion using Lagrange method, that is from the energy side of kinetic and the potential energy of the system, the equation of system motion is derived from the decrease as follows.

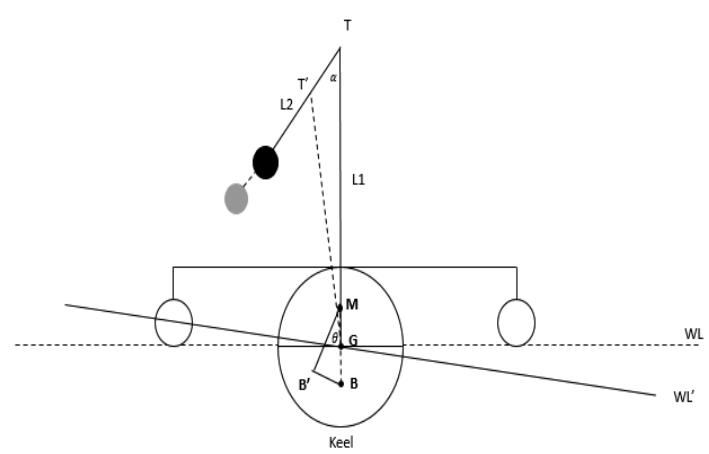

Fig 2. 6 Cylinder Pontoon and Pendulum from Front View

$$
\begin{gathered}
B B^{\prime}=B M \sin \theta \\
x_{1}=-B B^{\prime} \cos \theta \\
x_{1}=-B M \sin \theta \cos \theta \\
z_{1}=B B^{\prime} \sin \theta \\
z_{1}=B M \sin \theta \sin \theta \\
z_{2}=-\frac{G T}{B M}(-B M \sin \theta \cos \theta)-l_{2} \sin \theta \\
z=l_{2}(1-\cos \alpha)+\left(-\frac{G T}{B M}\right) B M \sin \theta \sin \theta
\end{gathered}
$$

Then the values of $\mathrm{x} 1$ and $\mathrm{y} 1$ are lowered once to get the speed function, after which it is fed into kinetic and potential equations. EK1 is the kinetic energy of the pontoon, EK2 is the kinetic energy of the pendulum, EP1 is the potential energy of the pontoon and EP2 is the potential energy of the pendulum.

$$
\begin{gathered}
E K_{1}=\frac{1}{2} m_{1}\left(\dot{x}_{1}{ }^{2}+\dot{z}_{1}{ }^{2}\right) \\
E K_{2}=\frac{1}{2} m_{2}\left(\dot{x}_{2}{ }^{2}+\dot{z}_{2}{ }^{2}\right) \\
E P_{1}=m_{1} g y_{1} \\
E P_{2}=m_{2} g y_{1}
\end{gathered}
$$

Then EK and EP become,

$$
\begin{gathered}
E K_{1}=\frac{1}{2} m_{1}\left(B M^{2}\right) \theta^{2} \\
E K_{2}=\frac{1}{2} m_{2}\left(G T^{2} \dot{\theta}^{2}+L_{2}{ }^{2} \dot{\alpha}^{2}-2 G T L_{2} \theta \dot{\alpha}\right) \\
E P_{1}=m_{1} g B M \sin \theta \sin \theta \\
E P_{2}=m_{2} g\left(-G T B M \sin \theta \sin \theta+L_{2}(1-\cos \alpha)\right)
\end{gathered}
$$

The Lagrange equation is searched by the following formula Langrange for $\theta$ is

$$
\frac{\partial}{\partial t}\left(\frac{\partial E K}{\partial \theta}\right)+\frac{\delta E P}{\delta \theta}-\frac{\delta E K}{\delta \theta}=Q
$$

$\mathrm{Q}$ is the excitation force of the ocean waves

$$
Q=A \sin \omega t
$$

Langrange for $\alpha$ is

$$
\frac{\partial}{\partial t}\left(\frac{\partial E K}{\partial \alpha}\right)+\frac{\delta E P}{\delta \alpha}-\frac{\delta E K}{\delta \alpha}=0
$$

The equation of motion obtained after using Lagrange and after replace it for pontoon and pendulum movements are as follows

The first equation

$$
\left(m_{1} B M^{2}\right) s^{2} \theta(s)+2 B M g \theta(s)=Q
$$


Value of Q after being Laplace is

$$
(A \cdot \sin (w \cdot t)) \text { laplace } \rightarrow \frac{A \cdot w}{s^{2}+w^{2}}
$$

The second equation of the pendulum after being Laplace as follows,

$$
\begin{aligned}
& \left(m_{2} G S^{2}-m_{2} G T l_{2}\right) s^{2} \theta(s)+m_{2}\left(G S l_{2}-l_{2}\right) s^{2} \alpha(s)- \\
& \left(2 m_{2} g G T\right) \theta(s)-\left(m_{2} g l_{2}\right) \alpha(s)=0
\end{aligned}
$$

Then, first and second equation become matrix, such as follow,

$$
\begin{gathered}
\left(\begin{array}{l}
\theta(s) \\
\alpha(s)
\end{array}\right)=\left(\begin{array}{cc}
m_{1} B M^{2} s^{2} & 0 \\
-m_{2} G T l_{2} s^{2} & m_{2} l_{2} s^{2}+m_{2} g l_{2}
\end{array}\right)^{-1}\left(\begin{array}{c}
\frac{A \omega}{s^{2}+\omega^{2}} \\
0
\end{array}\right) \\
\left(\begin{array}{c}
\theta(s) \\
\alpha(s)
\end{array}\right)=\left(\begin{array}{c}
\frac{A \omega}{\left(m_{1} B M^{2} s^{2}+2 g B M\right)\left(s^{2}+\omega^{2}\right)} \\
\frac{A G T l_{2} m^{2} s^{2} \omega}{\left(m_{2} l_{2}{ }^{2} s^{2}+g m_{2} l_{2}\right)\left(m_{1} B M^{2} s^{2}+2 g B M\right)\left(s^{2}+\omega^{2}\right)}
\end{array}\right)
\end{gathered}
$$

Inverse Laplace for both equation, then the equation of pontoon movement and pendulum is

$$
\begin{gathered}
\theta(t)=-\frac{2 A \omega \sin t \omega \sqrt{B M} g-\sqrt{2 A \omega \sin }\left(\frac{\sqrt{2} t \sqrt{B M g}}{B M \sqrt{m_{1}}}\right) B M \omega \sqrt{m_{1}}}{2 B M^{2} m_{1} \omega^{3} \sqrt{B M g}-4 B M g \omega \sqrt{B M g}} . \\
A G T \omega\left(\left(2 g l_{2}\right) \sin \left(t \sqrt{\frac{g}{l_{2}}}\right) \sqrt{\frac{g}{l_{2}}}-2 g l_{2} \sin (t \omega \omega) \omega+B M g m_{2} \sin (t \omega) \omega-B M l_{2} m_{2} \omega^{2}\right. \\
\sin \left(t \sqrt{\frac{g}{l_{2}}}\right) \sqrt{\frac{g}{l_{2}}}-\sqrt{2} B M g m_{2} \sin \left(\sqrt{2 t} \sqrt{\frac{g}{B M m_{2}}}\right)\left(\sqrt{\frac{g}{B M m_{2}}}\right)
\end{gathered}
$$

\section{Result and Discussion}

This chapter contains simulation validation, data analysis, and discussion. Analysis of data performed, the first analysis of pontoon motion against variations laden (high jukung), length jukung, and pendulum mass variation. The second data analysis, is the influence of pendulum deviation on the pontoons movement with variation laden, variations in the frequency of incoming waves, the mass and length of the pendulum arm.

\subsection{Validation of Simulation Result}

In this study, validation is done by calculating the pioneering deviation error (rolling motion) when the pontoons are exposed to waves in the actual state and simulation. Validation is also done based on the number of meshing in the simulation. Roll movement value is validated in this final project with water-laden variation $1 / 2 \mathrm{D}$ and $2 / 3 \mathrm{D}$ (large diameter of pontoon) at wave period condition 0.8 seconds.

The average error obtained is $8.098 \%$ explains the difference of experimental data value and simulation less than $10 \%$ then it is considered the mesh value and the simulation boundary condition is close to the experimental code so that it can be used to simulate the variation of water, pontoon support, and wave period.

Validation of experimental pendulum deviation and simulation using mathematical modelling was performed at a period of incident wave $0.6 \mathrm{~s}$ with mass and pendulum arm length is $20 \mathrm{~g}$ and $10.67 \mathrm{~cm}$. The maximum deviation of the experimental pendulum was 170 and the width of the pendulum of mathematical model was $14,290 \mathrm{deg}$.

\subsection{Response Amplitude Operator (RAO) of Pontoon}

The computational results of the pontoon movement response over the regular waves are arranged in the form of RAO curves as shown in Figure 4.1. Movement modes to be analyzed, roll, heave, and pitch with wave direction 900 and amplitude of $1.5 \mathrm{~cm}$ waves. Three Heave, roll, and pitch movement modes are three movements that have a dominant influence over the other three motions for floating free floating seas (Djatmiko, 2012). In relation to wave frequency variation, computation has been performed from incident wave frequency $1 \mathrm{~Hz}$ to $5 \mathrm{~Hz}$, when viewed from wave period, as opposed to from 0.2 seconds to 1 second. Next will be analyzed pontoons response in the frequency range with variations of pontoon $1 / 2$ and $2 / 3$ large diameter cylinder, a variation of jukung $1.5 \mathrm{~cm}$ and 4 $\mathrm{cm}$, a variation of jukung length $49.5 \mathrm{~cm}$ and $41.5 \mathrm{~cm}$ in each motion mode.

\subsubsection{Respons of Pontoon with Variation of Water Draft}

In this study, the authors will analyze the influence of variation on the pontoons response based on the roll, heave, and pitch graph of Response Amplitude Operator (RAO) which is done from frequency incident wave 1 $\mathrm{Hz}$ to $5 \mathrm{~Hz}$ at regular wave with an amplitude of $1.5 \mathrm{~cm}$ wave. The analysis of the laden influence was performed on the $1 \mathrm{st}$ and 9 th pontoon variations, ie at $49.5 \mathrm{~cm}$ jukung length, 40.6-gram pendulum load, and $16.5 \mathrm{~cm}$ pendulum arm length. Table variations of pontoons can be seen in more detail in Table I

The pattern of roll and heave motion response shows a similar pattern for laden $1 / 2$ or $2 / 3$ diameter. RAO motion roll and heave on laden $2 / 3$ diameter larger than the roll and heave on laden $1 / 2$ diameter. This corresponds to the height of the hull from the position of the keel that is exposed to the water, the greater the rolling movement will increase (Yoshiho Ikeda, 2012). In addition, the higher the water the ship the resulting heave movement is also increase (Andrian, 2010). Pitch movement response is similar to roll and heave movement response, but the pitch movement has a small value compared to roll and heaves this happens because the wave comes from the 900 directions so that the pitch movement becomes non-dominant. The pitch motion on the $2 / 3 \mathrm{D}$ load is very small, but when viewed from a smaller scale we will get the same line trend with roll, heave, and pitch motions. 


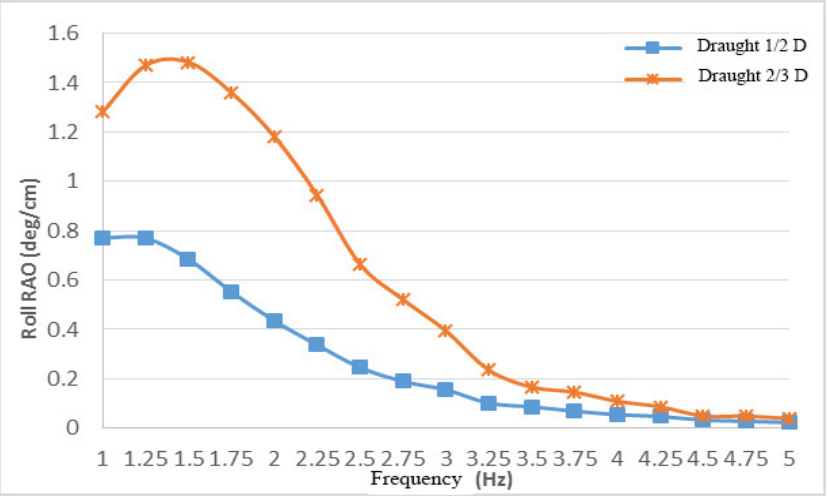

Fig 3.1 Roll RAO with Variation of Water Draft

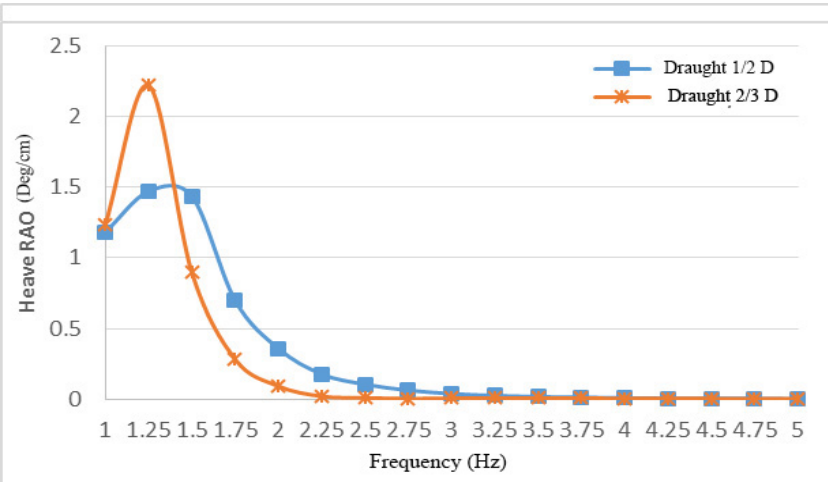

Fig 3.2 Heave RAO with Variation of Water Draft

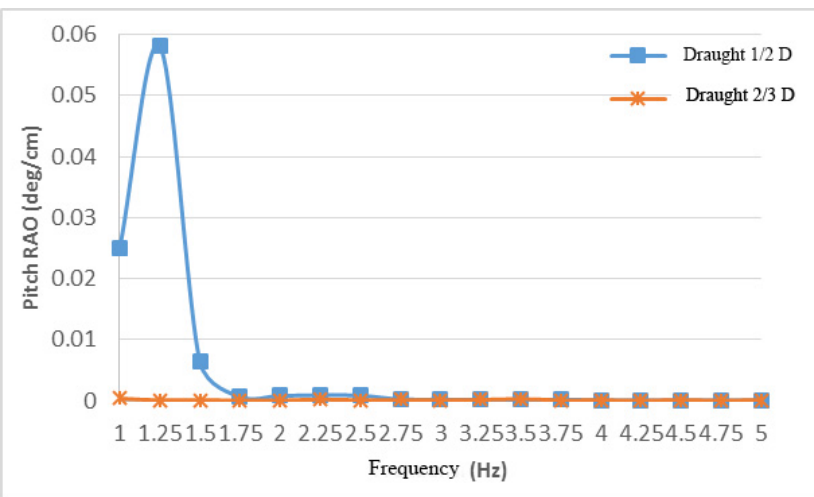

Fig 3.3 Pitch RAO with Variation of Water Draft

The graph above shows the movement response (RAO) roll, heave, and pitch on laden $1 / 2$ or $2 / 3$ after passing the frequency around $1.25 \mathrm{~Hz}-1.5 \mathrm{~Hz}$ decreased, meaning that if the pontoon is placed on the frequency increase or small period then the movement response will decrease. Thus, with a large or denser frequency between successive wave peaks, it will give the effect of a moving pontoon over a relatively flat water (Djatmiko, 2012). In Figure 3.2 the heave movement has decreased sharply after passing the 1.25 $\mathrm{Hz}$ wave frequency as well as the pitch motion of Figure 4.3, while in Figure 4.1 the roll value has a gentle slope, it can be concluded if the pontoon is put on wave frequency above $1.25 \mathrm{~Hz}$ roll movement will be more dominant compared to heave motion, while the pitch motion remains smaller than the roll and heave movement.

As mentioned earlier, the vertical pendulum in this study moves in the y-axis direction with the direction of the incident wave 900. This causes the pontoon roll movement mode to become more dominant to move the pendulum. Therefore, referring to the RAO chart of the above roll motion, the pontoon is more appropriate if it is placed on the frequency of the coming wave of $1 \mathrm{~Hz}-$ $1.75 \mathrm{~Hz}$.

\subsubsection{Response of Pontoon with Variation Length of Jukung}

Analysis of the effect of jukung length with a variation of $49.5 \mathrm{~cm}$ and $41.5 \mathrm{~cm}$ (variation 2 and 6 pontoons) on the motion of roll, heave, and pitch of pontoons performed on laden 1/2 diameter can be seen in Figure 4.4. The effect of variation of jukung on Roll, heave, and pitch motions is very small, seen from the trend of the coinciding line.

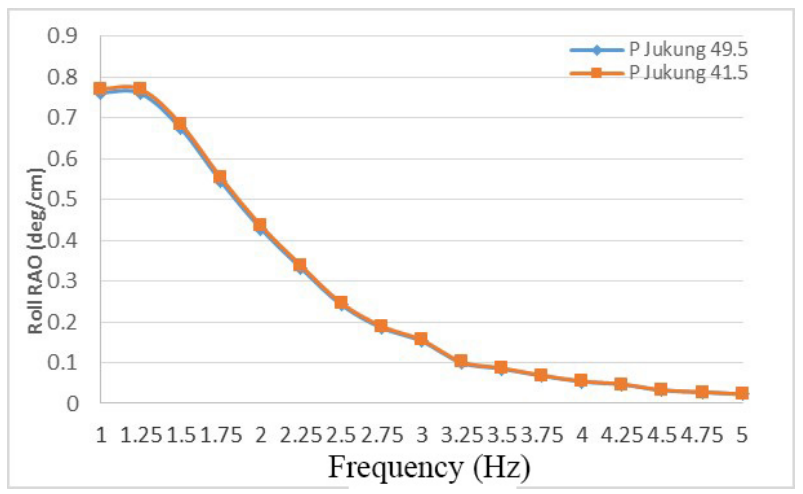

(a)

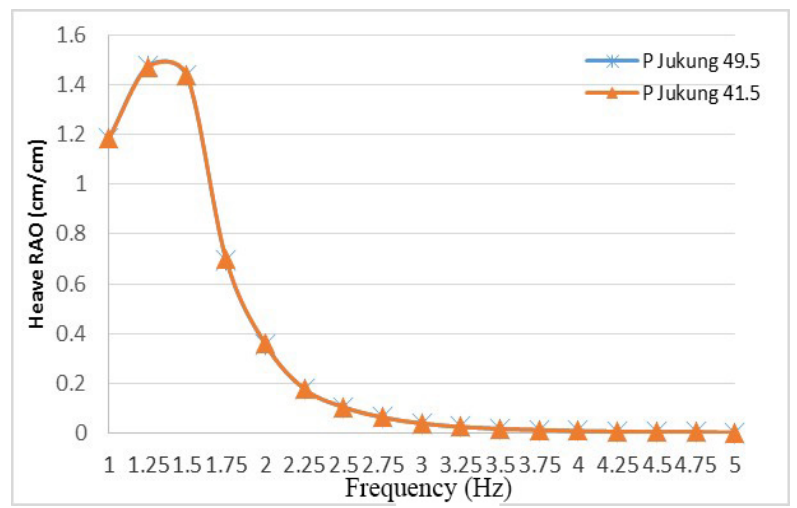

(b)

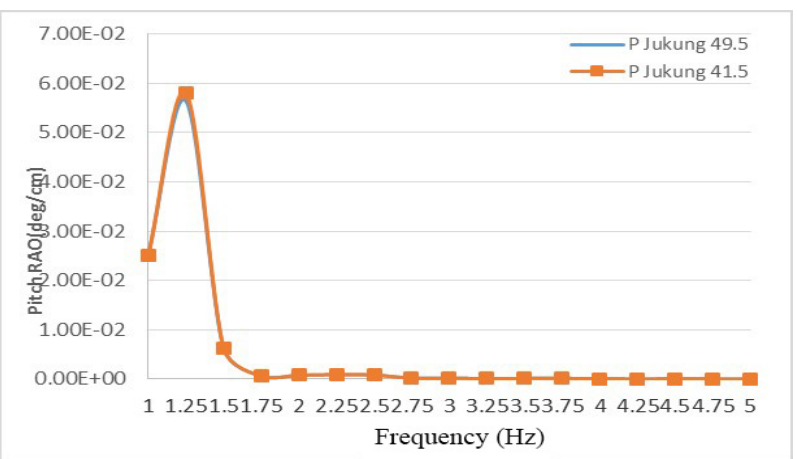

(c) 
Fig 3.4 Pontoon Movement with Variation Length of Jukung at $1 / 2$ D. (a) Roll (b) Heave (c) Pitch

Figure 3.5 is the motion response of roll pontoon, heave, and pitch variation of jukung length at $2 / 3$ diameter (variations to 11 and 15). The influence of variation of jukung length on Roll motion is very small, seen from the trend of the coinciding line. If the pontoon with a length of $49.5 \mathrm{~cm}$ jukung is at the frequency of sea wave $1.25 \mathrm{~Hz}$ large rolling angle is $1.46 \mathrm{deg} / \mathrm{cm}$ and heaving $2.1978 \mathrm{~cm} / \mathrm{cm}$, pontoon with long jukung 41.5 $\mathrm{cm}$ large rolling angle is $1.47 \mathrm{deg} / \mathrm{cm}$ and heaving is $2,292 \mathrm{~cm} / \mathrm{cm}$. It can be concluded a shorter jukung, 41.5 $\mathrm{cm}$, resulting in greater rolling and heaving motions although this movement difference is not significantly significant with $49.5 \mathrm{~cm}$ jukung length. In the pitching motion for $49.5 \mathrm{~cm}$ and 41.5 jukung length it also has a small difference, but the RAO pitch value at a different frequency of $1 \mathrm{~Hz}$, meaning that at a jukung 41.5 at $1 \mathrm{~Hz}$ frequency the pontoon moves larger, but the pitching is small compared to the other two motions.

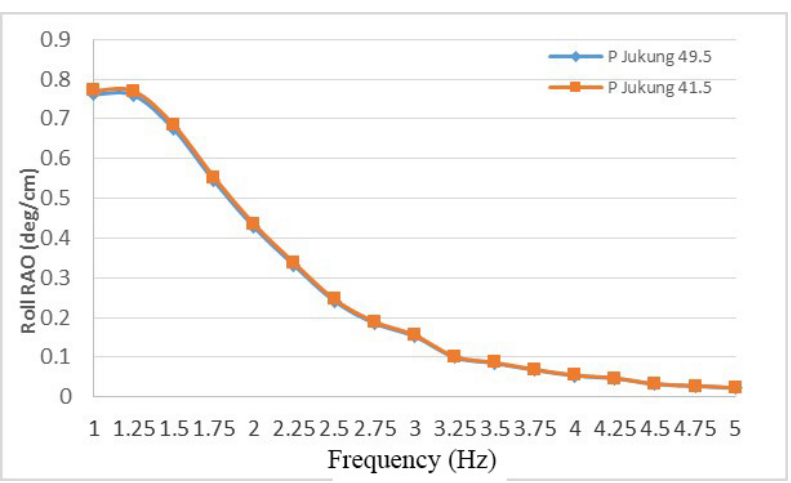

(a)

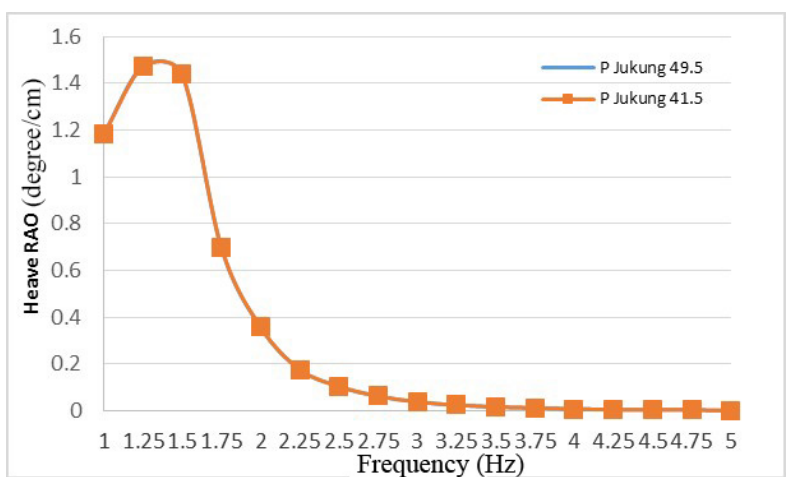

(b)

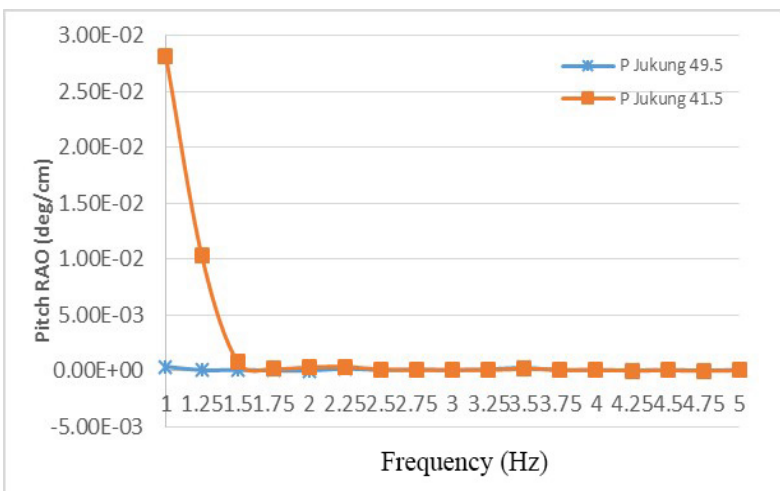

(c)

Fig 3.5 Pontoon Movement with Variation Length of Jukung at 2/3 D. (a) Roll (b) Heave (c) Pitch

It can be concluded that with the longer jukung the value of RAO roll will be smaller because with increasing length of jukung the pontoon will become more stable. This is in accordance with the principle of a trimaran vessel that has a separate hull configuration resulting in good stability with a small rolling acceleration angle with longer jukung length (Sari, 2012) and according to DR Berrett and CB Barrass (1999) by increasing the width of the ship (the length of the ship is considered fixed), then the ship will be more stable.

\subsection{Analyzation of Pendulum Movement}

The pendulum motion response is derived from the mathematical model of one degree of freedom of the pontoon and one degree of freedom of the pendulum. By finding the equation of motion for pendulum then plotted a graph of pendulum response in the form of pendulum deviation. The pendulum motion analysis will be based on pendulum mass variation, 40.6 gram and 19.9 gram, pendulum arm variation, $16.5 \mathrm{~cm}$ and $10.67 \mathrm{~cm}$, placed on the pontoon with variations of water $1 / 2$ and $2 / 3$ large diameter of the pontoon.

\subsubsection{Mass Variation of Pendulum Movement}

In this analysis, we will explain the results of pendulum motion with a mass variation of 40.6 grams and 19.9 grams placed on the pontoon with water-laden $2 / 3$ diameter (Figure 3.7) with a wave period of $0.8 \mathrm{~s}$

Referring to the variations of 21 and 23 pendulums (seen in Table 3.2) we see a graph depicting the relationship of time and deviation with two mass variations. The larger the pendulum mass, the smaller the pendulum's pendulum. The pendulum mass of 19.9 grams has a maximum deviation of 14.3750 , while the mass of 40.6 grams has a maximum deviation of 13,930 .

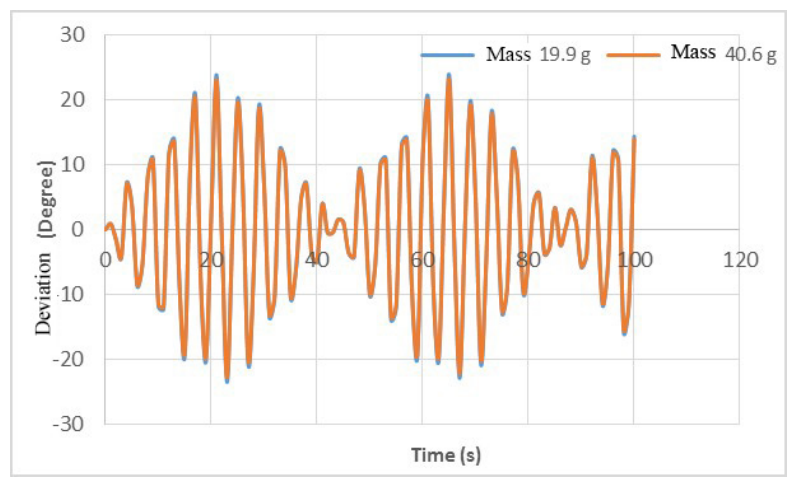

Fig 3.6 Respond of Pendulum with Mass Variation

\subsubsection{Arm Length Variation of Pendulum Movement}

In this analysis we will describe the pendulum motion with variation of pendulum arm length $16.5 \mathrm{~cm}$ and $10.67 \mathrm{~cm}$ placed on pontoon with water load $1 / 2$ 
diameter (Figure 4.9) and water is laden 2/3 large diameter of pontoon cylinder (Figure 4.10) with variation of period waves $0.4 \mathrm{~s}, 0.6 \mathrm{~s}$, and $0.8 \mathrm{~s}$ and 40.6 $\mathrm{g}$ of pendulum mass are fixed.

The figure below is a pendulum deviation graph with arm length variations at $0.4 \mathrm{~s}$ wave frequencies (1st and 2 nd pendulum variations), $0.6 \mathrm{~s}$ (5th and 6 th pendulum variations), and $0.8 \mathrm{~s}$ (variations of the 9 th and 10th pendulums) on laden pontoons $1 / 2$ large diameter cylinder. Table pendulum variation can be seen in table 3.2 .

Based on the response of the mathematical model formula, the pendulum movement on the pontoon with $1 / 2$ diameter of the large cylinder, when placed on the wave period $0.4 \mathrm{~s}, 0.6 \mathrm{~s}$, and $0.8 \mathrm{~s}$ has a similar movement. The $16.5 \mathrm{~cm}$ pendulum arm produces a small drift compared to the sleeve length of $10.67 \mathrm{~cm}$. According to the equation (2.3) where the length of the pendulum is proportional to the pendulum period, the pendulum arm is longer the pendulum period will be longer and the pendulum angle from the fixed position will be smaller. The maximum pendulum wavelength with the length of the arm $10.67 \mathrm{~cm}$ in the wave period $0.4 \mathrm{~s}$ is 2.70 , whereas if the coming wave period is $0.6 \mathrm{~s}$ the maximum pendulum pulse is 13,130 . The maximum pendulum width with the length of the arm $10.67 \mathrm{~cm}$ in the period of $0.8 \mathrm{~s}$ is 12,630 .

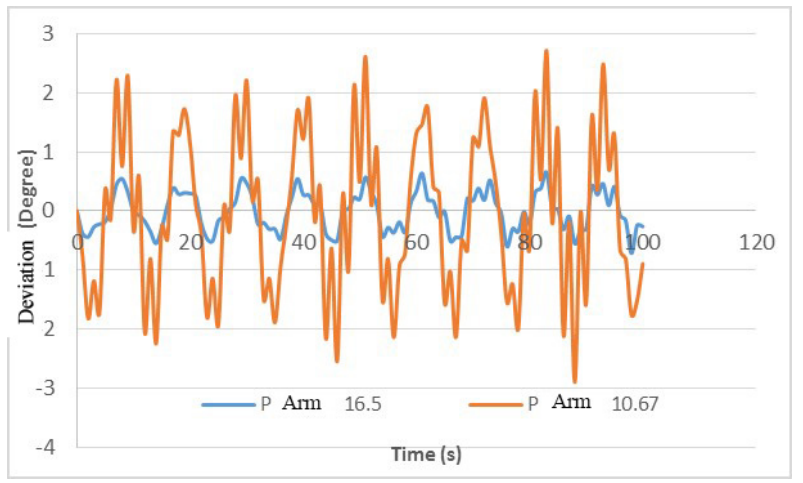

(a)

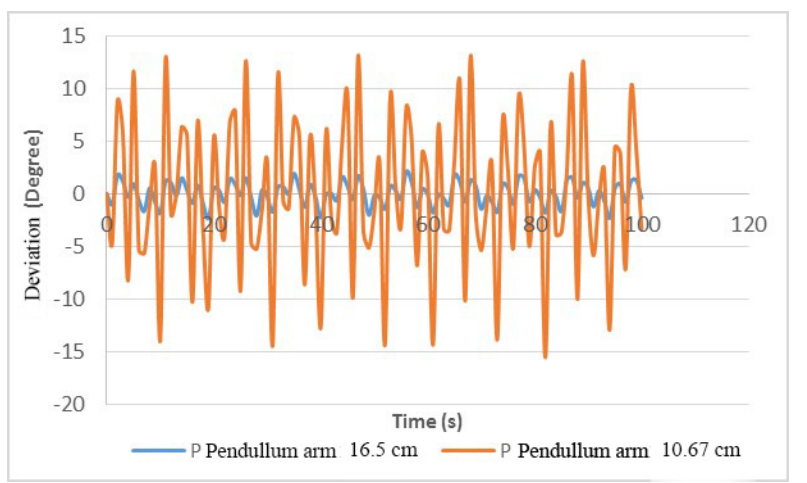

(b)

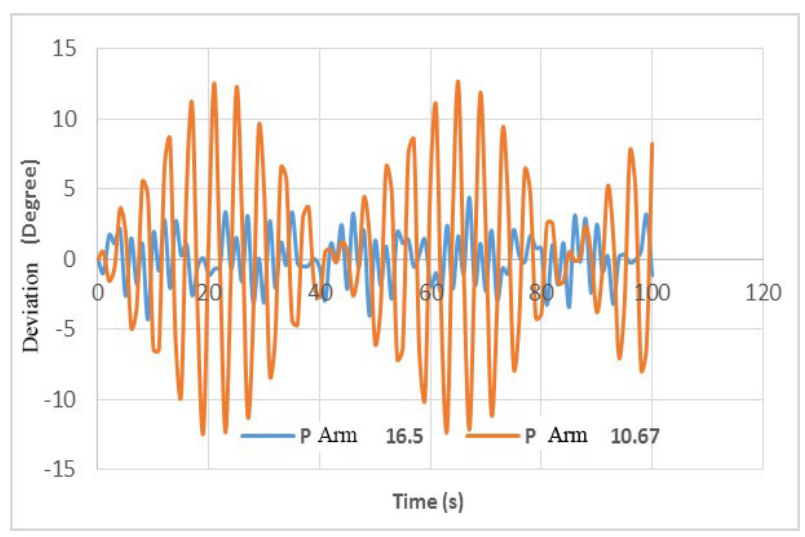

(c)

Fig 3.7 Respond of Pendulum with Length Variation with Wave Period (a) $0.4 \mathrm{~s}$ (b) $0.6 \mathrm{~s}$ (c) $0.8 \mathrm{~s}$.

The pendulum's intersection for pontoon with waterladen 2/3 large cylinder diameter and wave period $0.4 \mathrm{~s}$ is 2,330 . If the wave period is $0.6 \mathrm{~s}$, the maximum pendulum wavelength is 14.290. The maximum pendulum in the wave period of $0.8 \mathrm{~s}$ is 23.90 . According to the equation (2.3) where the length of the pendulum is proportional to the pendulum period, the pendulum arm is longer the wave period will be longer and the pendulum angle from the fixed position will be smaller.

Based on the analysis of the influence of variation of load, variation of arm length of the pendulum, and the variation in the frequency of incoming waves, it can be concluded that pendulum laid on laden $2 / 3$ will result in larger deviation, in accordance with analysis of 4.1 on the influence of the pontoon movement against variation Laden. Period of the waves are getting bigger it will cause the pendulum shrinkage is getting bigger too. Also, the shorter length of the pendulum arm will cause larger deviations.

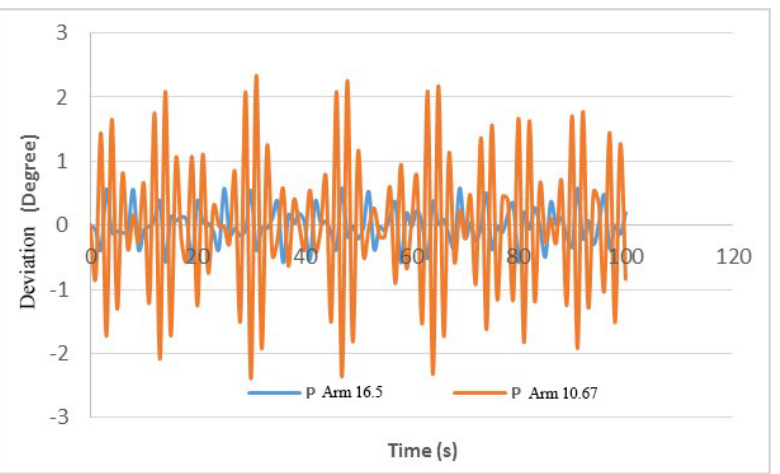

(a) 


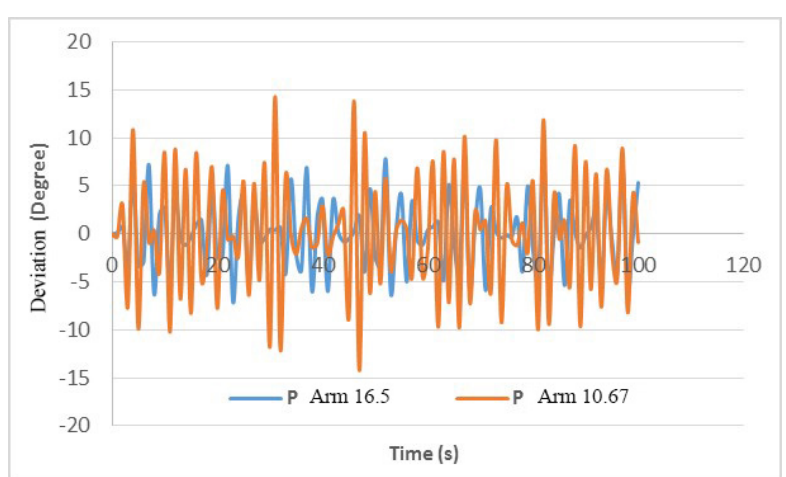

(b)

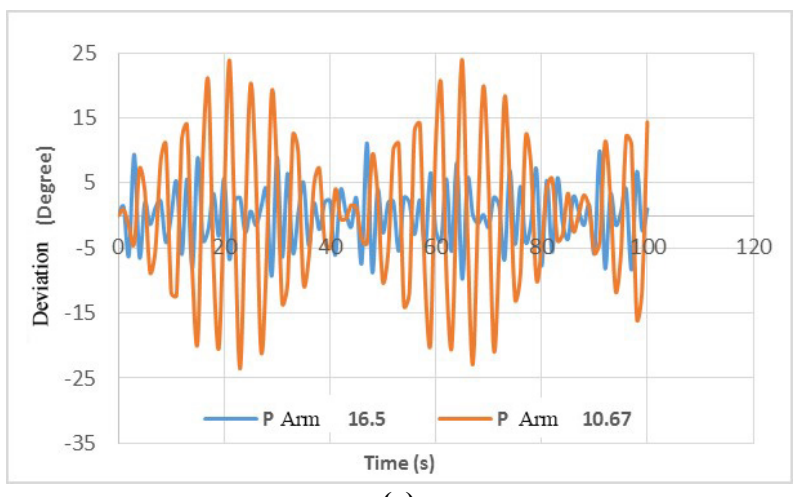

(c)

Fig 3.8 Respond of Pendulum with Length Variation in 2/3 D with Wave Period (a) $0.4 \mathrm{~s} \mathrm{(b)} 0.6 \mathrm{~s}$ (c) $0.8 \mathrm{~s}$.

\section{Discussion}

Marine Wave Power Generation - The Pendulum System (PLTGL-SB) is one of the renewable energy conversion technologies of ocean wave motion that will become the excitement style of the pendulum, wherein the pendulum will produce a drift which will be converted into electrical energy. This final project study uses a pontoon consisting of a large cylinder and two small cylinders as an outrigger, like a trimaran ship. To answer the purpose of this final project, simulated the pontoon movement on Ansys AQWA to determine the best pontoon motion for PLTGL-SB, then to know pendulum deviation done mathematical modeling one DOF pontoons and one DOF pendulum. The variations performed on this final project are variations of pontoons, ie $1 / 2$ and $2 / 3$ diameter of pontoon cylinder, outrigger length $49.5 \mathrm{~cm}$ and $41.5 \mathrm{~cm}$, pendulum mass 40.6 gram and 19.9 gram, and pendulum length $49.5 \mathrm{~cm}$ and $41.5 \mathrm{~cm}$ with amplitude of wave used $1.5 \mathrm{~cm}$, wave direction 900, and frequency range of wave $1 \mathrm{~Hz}-5 \mathrm{~Hz}$.

The simulated variation of jukung length, with longer length $(49.9 \mathrm{~cm})$ of rolling motion obtained is smaller in accordance with the principle principle of trimaran ship (due to pontoon pontoons such as trimaran vessels) where having a separate hull configuration produces good stability with angle small rolling acceleration with longer jukung length (Sari, 2012).

The simulation results with variations of $1 / 2$ and $2 / 3$ large diameter of pontoon are obtained to get the best pontoon motion based on RAO graph, then the best move on laden $2 / 3$ diameter. This corresponds to the height of the hull from the position of the keel that is exposed to the water, the greater the rolling movement will increase (Yoshiho Ikeda, 2012). In addition, the higher the water the ship the resulting heave movement is also increased (Andrian, 2010).

To obtain pendulum divergence, mathematical modeling was performed and a pendulum motion equation was obtained with one DOF pontoon (roll) and one DOF pendulum. The result of the plot of pendulum response of mass variation hence got bigger mass hence bigger resulted deviation small. The plot of the pendulum response variation in arms length obtained by the longer arm will result in smaller pendulum drift, according to the theory of equation 2.3.

Therefore, to get the best pontoon motion can be concluded pontoon with jukung length $41.5 \mathrm{~cm}$, laden water $2 / 3$ diameter, and placed in the period of $0.8 \mathrm{~s}$ wave will produce good pontoon movement so suitable for PLTGL-SB with mass 1919 gram pendulum, and a short pendulum arm, which is $10.67 \mathrm{~cm}$ to produce a larger deviation.

\section{Conclusion}

In accordance with the initial purpose of this research, which is to know the best pontoon form for PLTGL-SB and to know the largest deviation produced pendulum due to excitation style pontoon in laboratory scale, then from the analysis that has been done in the previous chapter, can be drawn conclusion as follows:

1. The best pontoon shape for PLTGL-SB based on the result, that is on the pontoon with high laden $2 / 3$ diameter big cylinder pontoon or with height jukung $1.5 \mathrm{~cm}$ and jukung length $41.5 \mathrm{~cm}$. Based on the response graph (RAO), the laboratory-scale pontoon in this study will result in maximum movement to move the pendulum if placed at a frequency of 1 $\mathrm{Hz}-1.75 \mathrm{~Hz}$.

2. The largest pendulum deviation is generated when the pontoon is placed in a $0.8 \mathrm{~s}$ wave period or a frequency of $1.25 \mathrm{~Hz}$, with a mass and a pendulum arm of $19.9 \mathrm{~g}$ and $10.67 \mathrm{~cm}$ with the largest deviation value being 23.50 .

The authors gratefully acknowledge funding support from Ministry of Research and Higher Education in Indonesia for a research grant.

\section{References}

1 F. C. Hongda Shi, Theoretical Study on the Power Take-Off Estimation of Heaving Buoy, Renewable Energy, 441- 448 (2014)

2 L. Rodrigues, Wave Power Conversion Systems for Electrical Energy Production, Renewable Energy, 1-7 (2012)

3 Besari Y. Mustofa, Analysis of Pontoon Model Motion on Tripod for Wave Energy ConverterPendulum System, Jurnal Teknik ITS.1:G-204 (2012) 
4 Sony Junianto, Analysis Of Pendulum Movements Due To The Pontoon Movements In Wave Energy Converter Pendulum Systems, Jurnal Teknik ITS.2(1):1 (2013) 